\title{
Tick-borne zoonotic agents infecting horses from an urban area in Midwestern Brazil: epidemiological and hematological features
}

\author{
João Bosco Vilela Campos ${ }^{1}$ - Filipe Santos Martins ${ }^{1}$. Carina Elisei de Oliveira ${ }^{1}$ - Amanda Alves Taveira ${ }^{1}$ \\ João Roberto de Oliveira ${ }^{1}$. Luiz Ricardo Gonçalves ${ }^{2} \cdot$ Matheus Dias Cordeiro $^{3}$ - Ana Claudia Calchi ${ }^{2}$. \\ Lina de Campos Binder ${ }^{4}$. Maria Carolina de Azevedo Serpa ${ }^{4}$. Amália Regina Mar Barbieri ${ }^{4} \cdot$ Marcelo B. Labruna $^{4}$. \\ Rosangela Zacarias Machado ${ }^{2} \cdot$ Gisele Braziliano de Andrade ${ }^{1} \cdot$ Marcos Rogério André $^{2} \cdot$ Heitor Miraglia Herrera $^{1}$
}

Received: 15 July 2021 / Accepted: 10 September 2021 / Published online: 22 September 2021

(C) The Author(s), under exclusive licence to Springer Nature B.V. 2021

\begin{abstract}
The emergence of tick-borne diseases has been reported as a serious problem in public health worldwide and many aspects of its epidemiology and effects on the health of its hosts are unclear. We aimed to perform an epidemiological study of tickborne zoonotic Rickettsia, Borrelia, and Anaplasmataceae in horses from Midwestern Brazil. We also evaluated whether Borrelia spp. and Anaplasmataceae may be associated with hematological disorders in the sampled animals. Blood and serum samples as well as ticks were collected from 262 horses. Serum samples were used to perform serological tests, and hematological analyses were made using whole blood. Furthermore, DNA extracted from whole blood and ticks was used for molecular tests. Campo Grande is enzootic for tick-borne studied bacteria, since we found an overall exposure of 59.9\% of the sampled horses, $28.7 \%$ of them presented co-exposure. Seropositivity rates of $20.6 \%$ for Borrelia spp., $25.6 \%$ for Rickettsia spp., and $31.6 \%$ for Anaplasmataceae were found in the sampled horses. Considering both molecular and serological tests for Borrelia spp., the infection rate was 48.0\% (126/262). None of the tested horses showed molecular positivity for Anaplasma phagocytophilum. The horses sampled displayed $7.2 \%$ of parasitism by ixodid ticks in single and coinfestations. We did not find DNA of any studied bacteria in the sampled ticks. Positive horses for Borrelia spp. and Anaplasmataceae agents displayed leukopenia, monocytopenia, and lymphopenia. Together, our results suggest that horses may play a role as sentinel host for zoonotic bacteria and Borrelia spp. and Anaplasmataceae agents can impair the health of horses.
\end{abstract}

Keywords Anaplasmataceae $\cdot$ Borrelia spp. $\cdot$ Rickettsia spp. $\cdot$ Sentinel hosts $\cdot$ Ticks

\section{Introduction}

Filipe Santos Martins

filipemsantos@outlook.com

$\bowtie$ Heitor Miraglia Herrera

filipemsantos@outlook.com

1 Laboratory Insana Huna, Interface Between Animal, Environmental and Human Health, Department of Biosaúde, University Católica Dom Bosco, Campo Grande, Mato Grosso Do Sul, Brazil

2 Immunoparasitology Laboratory, Department of Pathology, University Estadual Paulista, Campus Jaboticabal, Jaboticabal, São Paulo, Brazil

3 Laboratory of Parasitic Diseases, University Federal Rural Do Rio de Janeiro, Rio de Janeiro, Brazil

4 Department of Preventive Veterinary Medicine and Animal Health, University of São Paulo, São Paulo, Brazil
Horses have been reported infected with Anaplasma phagocytophilum and exposed to Borrelia burgdorferi and Rickettsia rickettsii, etiological agents of human granulocytic anaplasmosis (HGA), Lyme borreliosis (LB), and Brazilian spotted fever (BSF) in Brazil, respectively (Souza et al., 2016; Socoloski et al., 2018; Dos Santos et al., 2019). Ixodid tick vectors play an important role in the maintenance of these bacteria in endemic areas through efficient transmission mechanisms, such as transovarian transmission in the case of Rickettsia spp. (Piranda et al., 2011) and transstadial perpetuation in the cases of A. phagocytophilum and Borrelia spp. (Pusterla et al., 2002; Cordeiro et al., 2018). The role of ticks in the transmission of B. burgdorferi sensu lato (s.1.) or A. phagocytophilum (previously known as Ehrlichia equi) in Brazil remains unproven (Abel et al., 2000; Salvagni 
et al., 2010), in contrast to Ixodes sp. ticks in the northern hemisphere (Franke et al., 2013; Dugat et al., 2015). The species Rhipicephalus (Boophilus) microplus has been registered as a vector of Borrelia theileri to cattle and horses in the Brazilian territory, maintaining this bacterium by transovarian transmission (Yparraguirre et al., 2007; Cordeiro et al., 2018). Rickettsia rickettsii, the agent of BSF, is transmitted by Amblyomma sculptum, Amblyomma aureolatum, and Rhipicephalus sanguineus (s.l.) (De Oliveira et al., 2019).

In the state of Mato Grosso do Sul (MS), Midwestern Brazil, serological and molecular evidences of $B$. burgdorferi (s.l.) have been reported in humans (Resende et al., 2016; Lopes et al., 2017). Furthermore, the occurrence of Rickettsia species in the state of MS has been recorded in small wild mammals and in large wild rodent capybara (Hydrochoerus hydrochaeris) that have been reported as amplifying hosts for $R$. rickettsii (Souza et al., 2009), Amblyomma spp., $R$. sanguineus, and humans (De Almeida et al., 2013; Matias et al., 2015; Binder et al., 2017; De Sousa et al., 2018). Serological evidence of exposure to A. phagocytophilum was reported in Brazilian marsh deer (Blastocerus dichotomus) in the state of MS. Additionally, 16S rRNA Anaplasmataceae genotypes have been detected in dogs, coatis (Nasua nasua), and A. sculptum ticks in the Pantanal region, MS (Sacchi et al., 2012; André, 2018).

As horses do not present persistent bacteremia of $A$. phagocytophilum and B. burgdorferi (s.1.) (Burbelo et al., 2011; Socoloski et al., 2018; Dos Santos et al., 2019) and in the case of $R$. rickettsii, these animals are considered refractory to infection (Ueno et al., 2016), infected or exposed horses by these bacteria have been designated as sentinel hosts in endemic areas (Souza et al., 2016; Socoloski et al., 2018; Dos Santos et al., 2019). The aim of this study was to investigate the role of horses and their related ticks in the epidemiology of these zoonotic tick-borne bacteria in Campo Grande, MS, Midwestern Brazil. The association between serological exposure and/or molecular positivity for the selected agents with hematological parameters in infected horses was also assessed.

\section{Methods}

\section{Site collection and field procedures}

This study was performed in the municipality of Campo Grande, MS, Midwestern Brazil. Between November 2017 and April 2018, whole blood, serum samples, and ticks were collected from 262 horses that had been raised in that region. The animals were maintained in the facilities of the Jockey Club, equestrian riding school, and military police.
Sampling was carried out by the non-probabilistic method (Stevenson, 2005).

\section{Identification of collected ticks}

Ticks parasitizing horses were collected after a visual inspection of $60 \mathrm{~s}$ and identified using previously published dichotomous keys (Barros-Battessti et al., 2006; Nava et al., 2014).

\section{Hematological analysis}

Horse blood samples were collected in tubes with and without ethylenediamine tetra-acetic acid (EDTA). In the first $6 \mathrm{~h}$ after blood collection, the packed cell volume (PCV) was quantified using microhematocrit technique; the red blood cells (RBC) and white blood cells (WBC) were counted using an automated hematology analyzer (pocH-100iV Diff Veterinary Hematology Analyzer, Sysmex $\left.{ }^{\circledR}\right)$. The determination of total plasma proteins (TPP) was performed by manual refractometry, and fibrinogen (FIBRI) was assessed by heat precipitation technique in a water bath at $57{ }^{\circ} \mathrm{C}$ for 3 min (Kaneko et al., 1997). The monocytes, lymphocytes, neutrophils, eosinophils, and basophilic counts were performed by counting 100 leukocytes in a blood smear stained by the rapid method (Fast Panotic LB®), under light microscopy $(1000 \times)$.

We used the values of RBC, PCV, hemoglobin, mean corpuscular volume (MCV), and mean corpuscular hemoglobin concentration (MCHC) as indicators for anemia rates; monocyte and neutrophil counts as indicators for infection responses; lymphocyte count as indicators of immune investment; and fibrinogen and platelet count as indicators of coagulation (Kaneko et al., 1997; Parreira et al., 2016).

\section{Indirect enzyme-linked immunosorbent assay (ELISA) for detection of anti-B. burgdorferi antibodies}

Serum samples collected from horses were subjected to an ELISA assay using $B$. burgdorferi sensu stricto (s.s.) antigen G39/40 strain diluted to $20 \mathrm{mg} / \mathrm{mL}$ according to Socoloski et al. (2018). The sensitivity of the assay ranged from 82.6 to $100 \%$ in the analyses for IgG antibodies, according to Magnarelli et al. (1994).

The horse sera used as positive and negative controls (Socoloski et al., 2018) belonged to the serum bank of the Laboratory of Parasitic Diseases at the Federal Rural University of Rio de Janeiro (LDP-UFRRJ). Twelve negative controls and two positive control sera were used per plate. The cutoff point value was calculated based on the $t$-Student distribution with a $99.99 \%$ confidence interval, determined with the mean of the negative controls plus three times the 
standard deviation of the optical density (OD) values of the negative controls of each reaction. Still, to correct the OD of each plate, the cutoff value was equal to 100 , following the formula: (test serum OD $\times 100 /$ cutoff). The results of OD of the sera of the animals tested in the present study were expressed following the formula proposed by Frey et al. (1998) as an optical density index (ODI).

\section{Indirect immunofluorescence antibody test (IFAT) for detection of IgG antibodies against Rickettsia spp. and $A$. phagocytophilum}

In order to detect IgG antibodies to Rickettsia spp. of the spotted fever group (SFG), slides containing crude antigens derived from three Rickettsia isolates from Brazil-R. rickettsii strain Taiaçu, R. parkeri strain At24, and R. amblyommatis strain Ac37-were used (Labruna et al., 2004; Pinter and Labruna, 2006; Silveira et al., 2007). On each slide, previously determined non-reactive and reactive serum samples to SFG rickettsiae functioned as negative and positive controls, respectively. The slides were incubated with fluorescein isothiocyanate labeled anti-horse IgG (Sigma®Aldrich, St. Louis, USA) and examined under a fluorescence microscope (Olympus ${ }^{\circledR}$, Tokyo, Japan). The Rickettsia species identification and cutoff (1:64) were determined according to Horta et al. (2007).

Aiming to detect anti-A. phagocytophilum IgG antibodies, we used antigen (Webster strain, kindly supplied by Dr. John Stephen Dumler, from Uniformed Services University of the Health Sciences) obtained from HL-60 cellular culture in the Immunoparasitology Laboratory of University Estadual Paulista, UNESP Jaboticabal, São Paulo, Brazil. Positive and negative Chilean equine serum samples for A. phagocytophilum were used as controls (Hurtado et al., 2020). The cutoff of the test was 1:64.

\section{DNA extraction}

DNA extraction from the EDTA whole blood of horses was performed using the phenol chloroform protocol (Sambrook et al., 1989). For tick DNA extraction, the GT (Guanidine) protocol, as adapted by Sangioni et al. (2005), was performed. DNA concentration and absorbance ratio $(260 / 280 \mathrm{~nm})$ were measured using a spectrophotometer (Nanodrop, Thermo Fisher Scientific, USA).

\section{Conventional PCR assays}

To detect Borrelia sp. DNA, a conventional polymerase chain reaction (cPCR) was performed using primers that amplify a 500-bp fragment of the coding region of the conserved 23S rRNA gene: Fwd (5'-TAC CCA GCA CTT ACC CTT GG-3') and Rev (5'-AGT GCC AGG TGG GTA GTT
TG-3') (National Institute of Industrial Property-INPICase BR 102016 021,522 6). The DNA samples used as positive controls were isolated from B. burgdorferi (s.s.) strain G39/40 provided by Dr. Matheus Dias Cordeiro from LDP-UFRRJ. The PCR reaction was conducted according to Sal et al. (2008). For the detection of Anaplasma spp. in horses, a nested PCR assay (nPCR) was performed using primers directed to the 16S rRNA gene to amplify $932 \mathrm{bp}$ and $546 \mathrm{bp}$, according to Massung et al. (1998). A. phagocytophilum DNA used as positive control was kindly provided by Prof. Dr. John Stephen Dumler (Uniformed Services University of the Health Sciences, Bethesda, MD, USA).

The molecular testing of horses' ticks was performed using the rickettsial ompA gene (Regnery et al., 1991; Roux et al., 1996), and DNA of the R. parkeri strain NOD was used as positive control (Labruna et al., 2007) (for primer list, see Supplementary File 1: Table S1). Sterile ultrapure water was used as a negative control. We did not perform molecular tests for Rickettsia spp. from horses' blood samples due to the absence of rickettsemia in these animals, when experimentally infected with $R$. rickettsii (Ueno et al., 2016).

\section{Real-time PCR assay for A. phagocytophilum}

To detect $A$. phagocytophilum, a quantitative polymerase chain reaction (qPCR) assay was performed, using primers: Fwd (5'-AGT TTG ACT GGA ACA CAC CTG ATC-3') and Rev (5'-CTC GTA ACC AAT CTC AAG CTC AAC-3') and probe [FAM] TTA AGG ACA ACA TGC TTG TAG CTA TGG AAG GCA [TAMRA] directed to the coding region of the msp-2 gene, according to Drazenovich et al. (2006). Plasmids (IDT psmart, Integrated DNA Technologies $\left.{ }^{\circledR}\right)$ containing the target sequences and diluted from $10^{7}$ to $10^{0}$ were used as positive controls. The negative control used in the reaction was sterile ultrapure water.

\section{Purification, sequencing, and BLAST analysis of the obtained amplicons}

The products of Borrelia sp. 23S rRNA amplicons were purified by enzymatic treatment with ExoProStar ${ }^{\mathrm{TM}}$ (GE Healthcare), in accordance with the manufacturer's recommendations. The amplicons were sequenced in both directions using an automated system based on the dideoxynucleotide chain-termination method (Sanger et al. 1977).

The quality of the electropherograms obtained through the sequencing of the amplified products was visually analyzed using the program FinchTV 1.4.0. In addition, consensus sequences were obtained by analysis of the forward sequences using the CAP3 program (http://mobyle.pasteur.fr/cgi-bin/MobylePortal/portal.py). In order to perform sequence identity analysis, the amplified gene 
fragments were compared with those previously deposited in GenBank using the Basic Local Alignment Search Tool (BLASTn) (http://blast.ncbi.nlm.nih.gov/Blast.cgi). Finally, the obtained sequences were individually aligned with other sequences available from GenBank using ClustalW (Thompson et al., 1994) and adjusted with BioEdit 7.0.5.3 (Hall, 1999).

\section{Statistical analysis}

Descriptive statistic (mean and confidence interval) was applied to obtain the mean of hematological variables. The Shapiro-Wilk test served to establish whether the distribution was normal. Since horses are refractory to Rickettsia spp., seropositive animals were not included in hematological analysis. Therefore, a Kruskal-Wallis test was applied to determine the differences among negative animals, and Borrelia sp.- and Anaplasma sp.-positive animals. Post hoc Mann-Whitney tests were used to assess pair-wise results of the Kruskal-Wallis test. Finally, the Spearman correlation test was performed to assess whether there was a significant association between the seropositivity of the three bacteria studied, as well as among the seropositivity for Rickettsia spp. and A. phagocytophilum and molecular positivity for Borrelia spp. in the sampled horses.

The determination of the influences of exposure to $A$. phagocytophilum and positivity for Borrelia spp. in relation to anemia rates, infection responses, immune investment, coagulation, and TPP was carried out by path analysis. To reduce dimensions of anemia rates, infection responses, immune investment, and coagulation values, we used the principal coordinate analysis (PCA), a geometric technique that converts a matrix of distances between points in multivariate space into a projection that maximizes the amount of variation along a series of orthogonal axes. We used an $r$ value $\geq 0.60$ to interpret the results (positive or negative effect) of the path analysis. The variables were statistically significant for its $p$ values $\leq 0.05$. All data were analyzed using R 3.6.1 (R Development Core Team, 2015).

\section{Results}

We found that $25.6 \%(67 / 262)$ of the sampled horses were seropositive for Rickettsia spp. Among them, 19.8\% (52/262) showed seropositivity for $R$. rickettsii, $16.7 \%$ (44/262) for $R$. parkeri, and $17.5 \%$ (46/262) for R. amblyommatis (Table 1). Moreover, $75.0 \%$ of seropositive horses for $R$. rickettsii and $R$. parkeri showed serological titers lower than 1:256 (Table 1). A seroprevalence of $31.6 \%$ (83/262) was recorded for A. phagocytophilum, high number of the seropositive animals (85.4\%) with low serological titers (1:64 and 1:128) (Table 1). The search for anti-B. burgdorferi (s.l.) antibodies

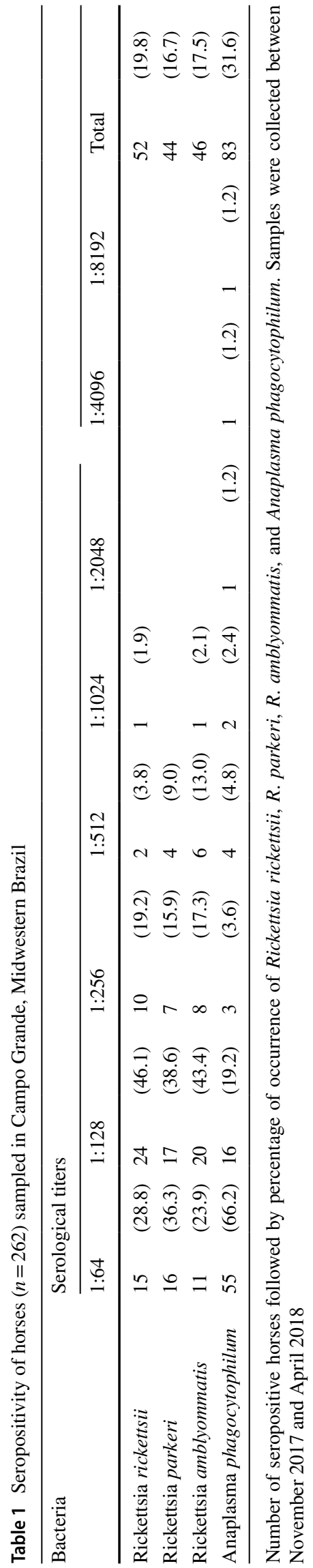


Fig. 1 Distribution of the optical density indexes of the test sera in relation to the cutoff point $(\mathrm{DO} \times 100 /$ cutoff point [black line]) obtained from the indirect ELISA assay for anti- $B$. burgdorferi antibodies in horses sampled between November 2017 and April 2018, in Campo Grande, Midwest Brazil


Fig. 2 Three-way Venn diagram illustrating single and co-reactivity for Anaplasma phagocytophilum, Borrelia burgdorferi (s.1.) and Rickettsia spp. in 262 horses sampled in Campo Grande, Midwest Brazil, between November 2017 and April 2018. Data were expressed by the total numbers followed by the percentage of occurrence

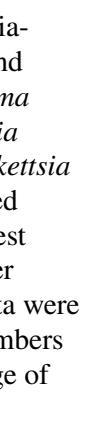


rate of $48.0 \%$ (126/262). Table 2 shows the patterns of Borrelia sp. infection in horses in Campo Grande, MS. None of the horses sampled showed molecular positivity for Anaplasma spp. and A. phagocytophilum test.

Tick infestations were observed in $7.2 \%$ (19/262) of the sampled horses, by Amblyomma sculptum (5 males and 3 females), Dermacentor nitens (16 males and 16 females), and Rhipicephalus (Boophilus) microplus (5 males and 32 females) and immature forms of Amblyomma spp. (1 nymph), D. nitens (36 nymphs), and $R$. (B.) microplus (19 nymphs). Among horses that presented positivity for Borrelia spp. $(n=126)$, we observed that six $(7.6 \%)$ were infested by adults of A. sculptum and R. (B.) microplus, and Amblyomma sp. and $R$. (B.) microplus nymphs. Furthermore, in horses seropositive for Rickettsia spp. and A. phagocytophilum, we found, respectively, ten (14.9\%) and six (7.2\%) infested by adults and immature forms for A. sculptum, $D$. nitens, and $R$. (B.) microplus. The molecular tests performed in the sampled ticks did not show the presence of the DNA of any vector-borne bacteria addressed in the present study.

The hematological mean values of horses infected and coinfected with A. phagocytophilum and Borrelia spp., as well as negative animals, are shown in Table 3. The hematological indexes of sampled horses showed that A. phagocytophilum-seropositive horses displayed significant decrease of WBC. Moreover, animals that displayed positivity in the molecular and serological tests for Borrelia spp. and coexposed to A. phagocytophilum displayed a significative decrease of monocyte count. In addition, positive horses by Borrelia spp. and exposed and co-exposed with A. phagocytophilum had a significant increase of MCV values.
Path analysis showed a positive influence of (i) A. phagocytophilum seropositivity (path coefficient $=0.18, p<0.05$ ); (ii) horses positive by Borrelia spp. (path coefficient $=0.13$, $p<0.05$ ); and (iii) serological exposure to A. phagocytophilum and positivity to Borrelia spp. (path coefficient $=0.16$, $p<0.05$ ) on anemia indicator, expressed by direct increase of MCV ( $r=0.90$ ) (Fig. 3). Additionally, our results showed that horses seropositive for A. phagocytophilum and positive to Borrelia spp. (path coefficient $=0.15, p<0.05$ ) were negatively influenced on immune investment expressed by decrease of lymphocyte count ( $r=-0.94)$ (Fig. 3).

Furthermore, Borrelia sp. positivity (path coefficient $=0.16, p<0.05$ ) and seropositivity for $A$. phagocytophilum and Borrelia spp. (path coefficient $=0.17, p<0.05$ ) resulted in the negative influence on the infection response, expressed by decreased monocyte count $(r=-0.79)$. Also, A. phagocytophilum with Borrelia spp. (path coefficient $=-0.14, p<0.05)$ had direct positive influence on TPP $(r=-0.98)$ (Fig. 3).

\section{Discussion}

Our results indicate that horses are constantly exposed to tick-borne bacteria in Campo Grande, Midwestern Brazil, due to seropositivity of $59.9 \%$, in single and multiple exposures. In this sense, horses can be considered sentinel hosts for the risk of infection by tick-borne bacteria to humans.

A general seroprevalence for Rickettsia spp. of $25.6 \%$ $(67 / 262)$ in sampled horses, even in low serological titers, and of $88.2 \%$ (15/17) for tested capybaras (data not shown),

Table 3 Hematological mean values of horses infected and coinfected with Anaplasma phagocytophilum and Borrelia spp. in the Campo Grande - Mato Grosso do Sul, between November 2017 and April 2018

\begin{tabular}{lclcc}
\hline Hematological values & Negatives $(n=88)$ & $\begin{array}{l}\text { Anaplasma phagocytophilum } \\
(n=43)\end{array}$ & Borrelia spp. $(n=84)$ & Coinfection $(n=35)$ \\
\hline RBC $10^{6} / \mu \mathrm{L}$ & $8.0(5.9-10.6)$ & $7.8(6.0-10.1)$ & $7.8(4.8-10.3)$ & $7.9(6.7-10.0)$ \\
Hemoglobin g/dL & $12(9-15)$ & $12(10-15)$ & $36(25-45)$ & $12(10-14)$ \\
PCV $\%$ & $36(27-47)$ & $37(27-45)$ & $46(39-52)^{\mathrm{b}}$ & $37(31-43)$ \\
MCV fL & $45(39-52)^{\mathrm{a}}$ & $47(42-50)^{\mathrm{b}}$ & $33(31-35)$ & $37(40-52)^{\mathrm{b}}$ \\
MCHC g/dL & $33(31-34)$ & $33(32-35)$ & $7(6-11)$ & $8(6-13)$ \\
TPP g/dL & $7(6-8)$ & $8(6-12)$ & $18(0-293)$ & $69(0-800)$ \\
FIBRI mg/dL & $3(0-1)$ & $24(0-200)$ & $133,238(27,150-225,950) 130,343(18,200-225,900)$ \\
Platelets $10^{3} / \mu \mathrm{L}$ & $139,875(58,175-225,650)$ & $136,163(46,300-230,000)$ & $8935(5553-12,193)$ & $8754(5655-14,200)$ \\
WBC $10^{3} / \mu \mathrm{L}$ & $9730(5653-14,578)^{\mathrm{a}}$ & $8398(5425-11,475)^{\mathrm{b}}$ & $5063(3024-7917)$ & $5054(2753-9308)$ \\
Neutrophils $10^{3} / \mu \mathrm{L}$ & $5256(2962-9867)$ & $4659(2980-6783)$ & $3319(1454-6124)$ & $3117(1282-5741)$ \\
Lymphocytes $10^{3} / \mu \mathrm{L}$ & $3802(1318-8123)$ & $3157(1077-4927)$ & $177(0-1011)^{\mathrm{b}}$ & $133(0-567)^{\mathrm{b}}$ \\
Monocytes $10^{3} / \mu \mathrm{L}$ & $289(0-1133)^{\mathrm{a}}$ & $228(0-766)^{\mathrm{a}}$ & $334(0-1731)$ & $328(0-1004)$ \\
Eosinophils $10^{3} / \mu \mathrm{L}$ & $342(0-1567)$ & $266(0-979)$ & $40(0-235)$ & $41(0-206)$ \\
Basophils $10^{3} / \mu \mathrm{L}$ & $38(0-308)$ & $38(0-180)$ & & \\
\hline
\end{tabular}

$R B C$, red blood cell counts $\left(\times 10^{6}\right) ; P C V$, packed cell volume; $M C V$, mean corpuscular volume; $M C H C$, mean corpuscular hemoglobin concentration; TPP, total plasma protein; $W B C$, white blood cell counts. Different letters denote statistical significance $(p<0.05)$ 
Fig. 3 Schematic representation of some hematological parameters with single and multiple infection patterns among tickborne agents in horses sampled in Campo Grande, Midwest Brazil, between November 2017 and April 2018


suggests the circulation of rickettsial agents in the studied area. Moreover, our results showed that horses were exposed to different SFG rickettsiae, because of their serological reactiveness to three species: $R$. rickettsii $(19.8 \%), R$. parkeri $(16.7 \%)$, and $R$. amblyommatis (17.5\%). These data, together with Alves et al. (2014), strengthen the occurrence of these rickettsial agents in the central west region of Brazil. Although we observed low infestations by A. sculptum in horses, probably due to good sanitary management to which the animals were submitted, we highlight the presence of A. sculptum because it is considered the main vector for $R$. rickettsia. Indeed, this tick species is found parasiting capybaras (Labruna et al., 2011; Szabó et al., 2013), the largest rodent extremely common in forest fragments in the CG that develop high rickettsia, and has anthropophilic habits (Souza et al., 2009; Polo et al., 2017; Ramírez-Hernández et al., 2020).

In the present study, we observed exposure to A. phagocytophilum in 31.6\% (83/262) of the collected horses, and nine seropositive animals showed high serological titers (1:512 to 1:8192). However, serological tests among Anaplasmataceae agents should be analyzed with caution, as the occurrence of cross-reactivity between species of Anaplasma and Ehrlichia has been reported in horses (Rolim et al., 2015; Vieira et al., 2016) and jaguars (Widmer et al., 2011). Additionally, we did not detect DNA of the A. phagocytophilum in the seropositive animals. In fact, the appropriate molecular target for A. phagocytophilum still represents a challenge for the diagnosis because genetic diversity according to their geographical distribution has been reported (De La Fuente et al., 2005; Silaghi et al., 2011). Herein, we used both 16S rRNA nested PCR and $m s p-2$ qPCR assays to screen the sampled horses for Anaplasma spp. Furthermore, experimental infection by A. phagocytophilum in horses showed that antibodies may persist for up to 300 days after inoculation, indicating that horses play a potential role as a sentinel of infections to human (Franzén et al., 2005, 2009). The presence of antibodies to A. phagocytophilum might represent a serological cross-reaction to Ehrlichia spp. previously detected in horses from Brazil (Vieira et al., 2016) or to a new Anaplasmataceae agent yet to be described.

The occurrence of $B$. burgdorferi in Brazilian territory still remains unclear due to the lack of isolation. Only molecular evidence in humans and a serological study in horses were reported (Resende et al., 2016; Lopes et al., 2017; Socoloski et al., 2018). Since B. theileri and $R$. (B.) microplus have been reported parasitizing bovines, ovine, and horses, in Brazil (Soares et al., 2000; Yparraguirre et al., 2007; Cordeiro et al., 2018), the seroprevalence of $20.6 \%$ found here may be due to cross-reactions with different species related to recurrent fever group (RFG) and cannot be ruled out (Magnarelli et al., 1994; Rogers et al., 1999). In fact, we found low rates of optical density for most seropositive horses. Moreover, the DNA detected in sampled horses may be related to infection by $B$. theileri since (i) bacteremia during $B$. burgdorferi infection is related as absent or brief (Chang et al., 2000; Maraspin et al., 2011; Talagrand-Reboul et al., 2020), (ii) the primers used here do not distinguish Borrelia species, and (iii) we found $R$. (B.) microplus infesting horses. Lack of molecular positivity for Borrelia spp. in the sampled ticks is expected because its detection has been recorded as negative (Montandon et al., 2014). Besides, the presence of DNA of Borrelia spp. in 32.3\% of sampled horses suggests that some reservoir mammal species must be participating as amplifying hosts for Borrelia spp. (Radolf et al., 2012) in the studied area. The combination of both molecular and serological tests may help to understand the different epidemiological patterns in a given host population. 
For example, the occurrence of $57.1 \%$ (72/126) of positive horses with early infection reinforces the enzootic character of the studied area. Additionally, the presence of $32.5 \%$ of positive horses (41/126) with a sub-patent infection strongly suggests that seropositive horses that displayed negativity in the molecular test fail in the transmission of tick-borne agents.

The leukopenia recorded in the present study could probably be associated to lysis of infected cells. Furthermore, our analysis showed that positivity of horses by both Borrelia spp. and Anaplasmataceae resulted in negative influences on the response to infection as well as immune investment, expressed by monocytopenia and lymphopenia, respectively. The decrease of leucocytes was also observed in naturally equine granulocytic anaplasmosis by Gribble (1969) and McQuiston et al. (2003), and lymphopenia was also reported in equines experimentally infected with A. phagocytophilum by Franzén et al. (2005). On the other hand, the resultant of infections may present differently as shown by Saleem et al. (2018) that recorded leukocytosis due to lymphocytosis and monocytosis in horses naturally infected by $A$. phagocytophilum. The hyperproteinemia found in horses that had contact to both Borrelia spp. and Anaplasmataceae in the present study suggests an increase in the production of immunoglobulins. When considered separately, A. phagocytophilum naturally infected horses did not display hyperproteinemia (Siska et al., 2013).

The interpretation of hematological results under natural infections should be done with caution whenever the kinetics of infection and the presence of other unrelated agents are unknown. However, comparing negative with positive sampled horses, we found an increase of MCV, indicating macrocytic anemia, as a result of vitamin $B_{12}$ deficiency (Satué et al., 2012). As the sampled animals had low fiber diet, and vitamin $B_{12}$ is naturally produced in the large intestine of horses due to the digestion of fibrous, it is possible that vitamin $B_{12}$ production could be compromised in these animals. Consequently, the observed increase in MCV values is mostly related to a low fiber diet than to the investigated bacteria.

\section{Conclusion}

The contact of horses with Rickettsia spp., Anaplasmataceae, and Borrelia spp. (s.l.) strongly suggests that Campo Grande, Midwest region of Brazil, is an enzootic area for tick-borne zoonotic bacteria. The absence of molecular positivity in all ticks collected indicates that horses do not present persistent bacteremia, suggesting that other mammal species in the studied area may play a role as amplifier hosts for these zoonotic agents. Horses in the studied area may play a role as a sentinel host for tick-borne zoonotic bacteria. Additionally, monocytopenia with lymphopenia found in positive horses by both Borrelia spp. and Anaplasmataceae can impair the health of horses.

Acknowledgements The authors would like to thank the owners of the farms for their availability to participate in the study, and the students of scientific initiation who helped in the collection and processing of the samples of the horses: João Victor, Diovana Lourencetti, Carol Domingos, and John Layno, and teacher Nubia de Oliveira.

Author contribution Conceptualization: João Bosco Vilela Campos, Marcos Rogério André, Carina Elisei de Oliveira, and Heitor Miraglia Herrera; Data curation: João Bosco Vilela Campos, Filipe Santos Martins, and Heitor Miraglia Herrera; Formal analysis: João Bosco Vilela Campos, Marcos Rogério André, Carina Elisei de Oliveira, Filipe Santos Martins, Marcelo B. Labruna, and Heitor Miraglia Herrera; Funding acquisition: Marcos Rogério André and Heitor Miraglia Herrera; Investigation: João Bosco Vilela Campos, Marcos Rogério André, Carina Elisei de Oliveira, Matheus Dias Cordeiro, Marcelo B. Labruna, Rosangela Zacarias Machado, and Heitor Miraglia Herrera; Methodology: João Bosco Vilela Campos, Filipe Santos Martins, Amanda Alves Taveira, João Roberto de Oliveira, Ana Claudia Calchi, Luiz Ricardo Gonçalves, Lina de Campos Binder, Maria Carolina de Azevedo Serpa, Amália Regina Mar Barbieri, Rosangela Zacarias Machado; Project administration: Heitor Miraglia Herrera; Supervision: Heitor Miraglia Herrera; Validation: João Bosco Vilela Campos, Marcos Rogério André, Carina Elisei de Oliveira, Filipe Santos Martins, Marcelo B. Labruna, Gisele Braziliano de Andrade, and Heitor Miraglia Herrera; Visualization: João Bosco Vilela Campos and Heitor Miraglia Herrera; Writing—original draft: João Bosco Vilela Campos; Writing—review and editing: João Bosco Vilela Campos, Marcos Rogério André, Carina Elisei de Oliveira, Filipe Santos Martins, Marcelo B. Labruna, Gisele Braziliano de Andrade, and Heitor Miraglia Herrera.

Funding This study was supported by Conselho Nacional de Desenvolvimento Científico e Tecnológico (CNPq) by Productivity Grants granted to the Heitor Miraglia Herrera (CNPq Process No. 308768/2017-5) and Marcos Rogério André (CNPq Process No. 302420/2017-7); Foundation for Support to the Development of Education, Science and Technology of the State of Mato Grosso do Sul (FUNDECT, Process 59/300.187/2016); and Foundation for Research Support of the State of São Paulo (FAPESP, Process 2018/02753-0). The present study was carried out with the support of the Coordination for the Improvement of Higher Education (CAPES) by a scholarship to the JBVC.

Data availability The datasets analyzed during the current study are available from the corresponding author on request.

\section{Declarations}

Ethical approval All methods were carried out in accordance with the guidelines and regulations of the National Council for Animal Experimentation (CONCEA). The procedures with the horses were approved by the Animal Use Ethics Committee (CEUA) of the Catholic University Dom Bosco, registration number 020/2017.

Conflict of interest The authors declare no competing interests. 


\section{References}

Abel, I.S., Marzagão, G., Yoshinari, N.H., Schumaker, T.T., 2000. Borrelia-like spirochetes recovered from ticks and small mammals collected in the Atlantic Forest Reserve, Cotia county, State of São Paulo, Brazil. Memorias do Instituto Oswaldo Cruz, 95(5), 621-624.

Alves Ada, S., Melo, A.L., Amorim, M.V., Borges, A.M., Gaíva, E., Silva, L., Martins, T.F., Labruna, M.B., Aguiar, D.M., Pacheco, R.C., 2014. Seroprevalence of Rickettsia spp. in Equids and Molecular Detection of 'Candidatus Rickettsia amblyommii' in Amblyomma cajennense Sensu Lato Ticks from the Pantanal Region of Mato Grosso, Brazil. Journal of Medical Entomology, 51(6), 1242-1247.

André, M.R., 2018. Diversity of Anaplasma and Ehrlichia/Neoehrlichia Agents in Terrestrial Wild Carnivores Worldwide: Implications for Human and Domestic Animal Health and Wildlife Conservation. Frontiers in Veterinary Science, 23(5), 293.

Barros-Battessti, D.M., Arzua, M., Bechara, G.H., 2006. Carrapatos de importância médico-veterinária da Região Neotropical: um guia ilustrado para identificação das espécies. Vox/ICTTD-3/ Butantan, São Paulo, Brazil.

Binder, L.C., Krawczak, F.S., Sponchiado, J., Melo, G.L., MoraesFilho, J., Bastos, F.A.N., Cáceres, N.C., Labruna, M.B., 2017. Serosurvey of Rickettsia spp. in small mammals from Mato Grosso do Sul state, Brazil. Ciência Rural, Santa Maria, 47, e20160476.

Burbelo, P.D., Bren, K.E., Ching, K.H., Coleman, A., Yang, X., Kariu, T., Iadarola, M.J., Pal, U., 2011. Antibody profiling of Borrelia burgdorferi infection in horses. Clinical and Vaccine Immunology, 18(9), 1562-1567.

Chang, Y.F., Novosol, V., McDonough, S.P., Chang, C.F., Jacobson, R.H., Divers, T., Quimby, F.W., Shin, S., Lein, D.H., 2000. Experimental infection of ponies with Borrelia burgdorferi by exposure to Ixodid ticks. Veterinary Pathology, 37(1), 68-76.

Cordeiro, M.D., Bahia, M., Magalhães-Matos, P.C., Cepeda, M.B., Guterres, A., Fonseca, A.H., 2018. Morphological, molecular and phylogenetic characterization of Borrelia theileri in Rhipicephalus microplus. Revista Brasileira de Parasitologia Veterinária, 27(4), 555-561.

De Almeida, R.F., Garcia, M.V., Cunha, R.C., Matias, J., Silva, E.A., De Fatima Cepa Matos, M., Andreotti, R., 2013. Ixodid fauna and zoonotic agents in ticks from dogs: first report of Rickettsia rickettsii in Rhipicephalus sanguineus in the state of Mato Grosso do Sul, mid-western Brazil. Experimental and Applied Acarology, 60(1), 63-72.

De la Fuente, J., Torina, A., Caracappa, S., Tumino, G., Furlá, R., Almazán, C., Kocan, K.M., 2005. Serologic and molecular characterization of Anaplasma species infection in farm animals and ticks from Sicily. Veterinary Parasitology, 133(4), 357-362.

De Oliveira, P.B., Harvey, T.V., Fehlberg, H.F., Rocha, J.M., Martins, T.F., Da Acosta, I.C.L., Labruna, M.B., Faccini, J.L.H., Albuquerque, G.R., 2019. Serologic and molecular survey of Rickettsia spp. in dogs, horses and ticks from the Atlantic rainforest of the state of Bahia, Brazil. Experimental and Applied Acarology, 78(3), 431-442.

De Sousa, K.C.M., Herrera, H.M., Rocha, F.L., Costa, F.B., Martins, T.F., Labruna, M.B., Machado, R.Z., André, M.R., 2018. Rickettsia spp. among wild mammals and their respective ectoparasites in Pantanal wetland, Brazil. Ticks and Tick-borne Diseases, 9(1), 10-17.

Dos Santos, T.M., Roier, E.C.R., Pires, M.S., Santos, H.A., Vilela, J.A.R., Peckle, M., Paulino, P.G., Baldani, C.D., Massard, C.L., 2019. Molecular evidence of Anaplasma phagocytophilum and
Theileria equi coinfection in horses from Rio de Janeiro, Brazil. Veterinary and Animal Science, 20(7), 100055.

Drazenovich, N., Foley, J., Brown, R.N., 2006. Use of real-time quantitative PCR targeting the msp2 protein gene to identify cryptic Anaplasma phagocytophilum infections in wildlife and domestic animals. Vector-Borne and Zoonotic Diseases, 6(1), 83-90.

Dugat, T., Lagrée, A.C., Maillard, R., Boulouis, H.J., Haddad, N., 2015. Opening the black box of Anaplasma phagocytophilum diversity: current situation and future perspectives. Frontiers in Cellular and Infection Microbiology, 14(5), 61.

Franke, J., Hildebrandt, A., Dorn, W., 2013. Exploring gaps in our knowledge on Lyme borreliosis spirochaetes--updates on complex heterogeneity, ecology, and pathogenicity. Ticks and Tick-borne Diseases, 4(1-2), 11-25.

Franzén, P., Aspan, A., Egenvall, A., Gunnarsson, A., Aberg, L., Pringle, J., 2005. Acute clinical, hematologic, serologic, and polymerase chain reaction findings in horses experimentally infected with a European strain of Anaplasma phagocytophilum. Journal of Veterinary Internal Medicine, 19(2), 232-239.

Franzén, P., Aspan, A., Egenvall, A., Gunnarsson, A., Karlstam, E., Pringle, J., 2009. Molecular evidence for persistence of Anaplasma phagocytophilum in the absence of clinical abnormalities in horses after recovery from acute experimental infection. Journal of Veterinary Internal Medicine, 23(3), 636-642.

Frey, A., Di Canzio, J., Zurakowski, D., 1998. A statistically defined endpoint titer determination method for immunoassays. Journal of Immunological Methods 221 (1-2), 35-41.

Gribble, D.H., 1969. Equine ehrlichiosis. Journal of the American Veterinary Medical Association, 155(2), 462-469.

Hall, E., Parton, R., Wardlaw, A.C., 1999. Time-course of infection and responses in a coughing rat model of pertussis. Journal of Medical Microbiology, 48(1), 95-98.

Horta, M.C., Labruna, M.B., Pinter, A., Linardi, P.M., Schumaker, T.T., 2007. Rickettsia infection in five areas of the state of São Paulo, Brazil. Memorias do Instituto Oswaldo Cruz, 102(7), 793-801.

Hurtado, C., Torres, R., Pérez-Macchi, S., Sagredo, K., Uberti, B., De Souza Zanatto, D.C., Machado, R.Z., André, M.R., Bittencourt, P., Müller, A., 2020. Serological and molecular detection of Anaplasma phagocytophilum in Thoroughbred horses from Chilean racecourses. Ticks and Tick-borne Diseases, 11(4), 101441.

Kaneko, J.J., Harvey, J.W., Bruss, M.L., 1997. Clinical biochemistry of domestic animals. 5. ed. San Diego: Academic Press 932.

Labruna, M.B., Whitworth, T., Bouyer, D.H., McBride, J., Camargo, L.M., Camargo, E.P., Popov, V., Walker, D.H., 2004. Rickettsia bellii and Rickettsia amblyommii in Amblyomma ticks from the State of Rondônia, Western Amazon, Brazil. Journal of Medical Entomology, 41(6), 1073-1781.

Labruna, M.B., Horta, M.C., Aguiar, D.M., Cavalcante, G.T., Pinter, A., Gennari, S.M., Camargo, L.M., 2007. Prevalence of Rickettsia infection in dogs from the urban and rural areas of Monte Negro municipality, western Amazon, Brazil. Vector-Borne and Zoonotic Diseases, 7(2), 249-255.

Labruna, M.B., Soares, J.F., Martins, T.F., Soares, H.S., Cabrera, R.R., 2011. Cross-mating experiments with geographically different populations of Amblyomma cajennense (Acari: Ixodidae). Experimental and Applied Acarology, 54(1), 41-49.

Lopes, F.A., Rezende, J., Silva, D.B.D.S., Alves, F.C.G., Oliveira, C.E., Costa, I.P.D., 2017. Molecular evidence of Borrelia burgdorferi sensu lato in patients in Brazilian central-western region. Revista Brasileira de Reumatologia. English, 57(6), 641-645.

Magnarelli, L.A., Anderson, J.F., Johnson, R.C., Nadelman, R.B., Wormser, G.P., 1994. Comparison of different strains of Borrelia burgdorferi sensu lato used as antigens in enzyme-linked immunosorbent assays. Journal of Clinical Microbiology, 32(5), 1154-1158. 
Maraspin, V., Ogrinc, K., Ružić-Sabljić, E., Lotrič-Furlan, S., Strle, F., 2011. Isolation of Borrelia burgdorferi sensu lato from blood of adult patients with borrelial lymphocytoma, Lyme neuroborreliosis, Lyme arthritis and acrodermatitis chronica atrophicans. Infection, 39(1), 35-40.

Massung, R.F., Slater, K., Owens, J.H., Nicholson, W.L, Mather, T.N., Solberg, V.B., Olson, J.G., 1998. Nested PCR assay for detection of granulocytic ehrlichiae. Journal of Clinical Microbiology, 36(4), 1090-1095.

Matias, J., Garcia, M.V., Cunha, R.C., Aguirre, A.de A., Barros, J.C., Csordas, B.G., Andreotti, R., 2015. Spotted fever group Rickettsia in Amblyomma dubitatum tick from the urban area of Campo Grande, Mato Grosso do Sul, Brazil. Ticks and Tickborne Diseases, 6(2), 107-110.

McQuiston, J.H., McCall, C.L., Nicholson, W.L., 2003. Ehrlichiosis and related infections. Journal of the American Veterinary Medical Association, 223(12), 1750-1756.

Montandon, C.E., Yoshinari, N.H., Milagres, B.S., Mazioli, R., Gomes, G.G., Moreira, H.N., Padilha, A.de F., Wanderley, G.G., Mantovani, E., Galvão, M.A., Langoni, H., Mafra, C., 2014. Evidence of Borrelia in wild and domestic mammals from the state of Minas Gerais, Brazil. Revista Brasileira de Parasitologia Veterinária, 23(2), 287-290.

Nava, S., Beati, L., Labruna, M.B., Cáceres, A.G., Mangold, A.J., Guglielmone, A.A., 2014. Reassessment of the taxonomic status of Amblyomma cajennense with the description of three new species, Amblyomma tonelliae n. sp., Amblyomma interandinum n. sp. and Amblyomma patinoi n. sp., and reinstatement of Amblyomma mixtum, and Amblyomma sculptum (Ixodida: Ixodidae). Ticks and Tick-borne Diseases, 5(3), 252-276.

Parreira, D.R., Jansen, A.M., Abreu, U.G., Macedo, G.C., Silva, A.R., Mazur, C., Andrade, G.B., Herrera, H.M., 2016. Health and epidemiological approaches of Trypanosoma evansi and equine infectious anemia virus in naturally infected horses at southern Pantanal. Acta Tropica, 163, 98-102.

Pinter, A., Labruna, M.B., 2006. Isolation of Rickettsia rickettsii and Rickettsia bellii in cell culture from the tick Amblyomma aureolatum in Brazil. Annals of the New York Academy of Sciences, 1078, 523-529.

Piranda, E.M., Faccini, J.L., Pinter, A., Pacheco, R.C., Cançado, P.H., Labruna, M.B., 2011. Experimental infection of Rhipicephalus sanguineus ticks with the bacterium Rickettsia rickettsii, using experimentally infected dogs. Vector-Borne and Zoonotic Diseases, 11(1), 29-36.

Polo, G., Mera Acosta, C., Labruna, M.B., Ferreira, F., 2017. Transmission dynamics and control of Rickettsia rickettsii in populations of Hydrochoerus hydrochaeris and Amblyomma sculptum. PLOS Neglected Tropical Diseases, 11(6), e0005613.

Pusterla, N., Chae, J.S., Kimsey, R.B., Berger Pusterla, J., DeRock, E., Dumler, J.S., Madigan, J.E., 2002. Transmission of Anaplasma phagocytophila (human granulocytic ehrlichiosis agent) in horses using experimentally infected ticks (Ixodes scapularis). Journal of veterinary medicine. B, Infectious diseases and veterinary public health, 49(10), 484-488.

Radolf, J.D., Caimano, M.J., Stevenson, B., Hu, L.T., 2012. Of ticks, mice and men: understanding the dual-host lifestyle of Lyme disease spirochaetes. Nature Reviews Microbiology, 10(2), 87-99.

Ramírez-Hernández, A., Uchoa, F., Serpa, M.C.A., Binder, L.C., Souza, C.E., Labruna, M.B., 2020. Capybaras (Hydrochoerus hydrochaeris) as amplifying hosts of Rickettsia rickettsii to Amblyomma sculptum ticks: Evaluation during primary and subsequent exposures to $R$. rickettsii infection. Ticks and Tick-borne Diseases, 11(5), 101463.

R Development Core Team. 2015. R: a language and environment for statistical computing. http://www.R-project.org [07 march 2019].
Regnery, R.L., Spruill, C.L., Plikaytis, B.D., 1991. Genotypic identification of rickettsiae and estimation of intraspecies sequence divergence for portions of two rickettsial genes. Journal of Bacteriology, 173(5), 1576-1589.

Resende, J., Lopes, F.A., Alves, F.C.G., Bruno, A.R., Moreno, S.E., Costa, I.P., Fonseca, A.H., Cordeiro, M.D., Oliveira, C.E., 2016. Detection of Borrelia burgdorferi sensu lato in Mato Grosso Do Sul, Brazil. JSM Tropical Medicine and Research, 1, 1003.

Rogers, A.B., Smith, R.D., Kakoma, I., 1999. Serologic cross-reactivity of antibodies against Borrelia theileri, Borrelia burgdorferi, and Borrelia coriaceae in cattle. American Journal of Veterinary Research, 60(6), 694-697.

Rolim, M.F., De Oliveira, F.C.R., Graça, F.A.S., Brasil, F.C., 2015. Serological evidence of exposure to Anaplasma phagocytophilum in horses from the Rio de Janeiro state mounted police bred in the urban zone. Ciência Animal Brasileira, 16, 3.

Roux, V., Fournier, P.E., Raoult, D., 1996. Differentiation of spotted fever group rickettsiae by sequencing and analysis of restriction fragment length polymorphism of PCR-amplified DNA of the gene encoding the protein rOmpA. Journal of Clinical Microbiology, 34(9), 2058-2065.

Sacchi, A.B., Duarte, J.M., André, M.R., Machado, R.Z., 2012. Prevalence and molecular characterization of Anaplasmataceae agents in free-ranging Brazilian marsh deer (Blastocerus dichotomus). Comparative Immunology, Microbiology \& Infectious Diseases, 35(4), 325-334.

Sal, M.S., Li, C., Motalab, M.A., Shibata, S., Aizawa, S., Charon, N.W., 2008. Borrelia burgdorferi uniquely regulates its motility genes and has an intricate flagellar hook-basal body structure. Journal of Bacteriology, 190(6), 1912-1921.

Saleem, S., Ijaz, M., Farooqi, S.H., Rashid, M.I., Khan, A., Masud, A., Aqib, A.I., Hussain, K., Mehmood, K., Zhang, H., 2018. First molecular evidence of equine granulocytic anaplasmosis in Pakistan. Acta Tropica, 180, 18-25.

Salvagni, C.A., Dagnone, A.S., Gomes, T.S., Mota, J.S., Andrade, G.M., Baldani, C.D., Machado, R.Z., 2010. Serologic evidence of equine granulocytic anaplasmosis in horses from central West Brazil. Revista Brasileira de Parasitologia Veterinária, 19(3), 135-140.

Sambrook, J., Fritsch, E.F., Maniatis, T., 1989. Molecular Cloning. A Laboratory Manual. $2^{a}$ ed. Cold Spring Harbor: Cold Spring Harbor Laborat Press.

Sanger, F., Nicklen, S., Coulson, A.R., 1977. DNA sequencing with chain-terminating inhibitors. Proceedings of the National Academy of Sciences, 74(12): 5463-5467.

Sangioni, L.A., Horta, M.C., Vianna, M.C., Gennari, S.M., Soares, R.M., Galvão, M.A., Schumaker, T.T., Ferreira, F., Vidotto, O., Labruna, M.B., 2005. Rickettsial infection in animals and Brazilian spotted fever endemicity. Emerging Infectious Diseases, 11(2), 265-270.

Satué, K., Hernández, A., Muñoz, A., 2012. Physiological Factors in the Interpretation of Equine Hematological Profile. Hematology - Science and Practice. School of Vet Med, University of Córdoba pp. 573-575.

Silaghi, C., Liebisch, G., Pfister, K., 2011. Genetic variants of Anaplasma phagocytophilum from 14 equine granulocytic anaplasmosis cases. Parasites \& Vectors, 16(4), 161.

Silveira, I., Pacheco, R.C., Szabó, M.P., Ramos, H.G., Labruna, M.B., 2007. Rickettsia parkeri in Brazil. Emerging Infectious Diseases, 13(7), 1111-1113.

Siska, W.D., Tuttle, R.E., Messick, J.B., Bisby, T.M., Toth, B., Kritchevsky, J.E., 2013. Clinicopathologic characterization of six cases of equine granulocytic anaplasmosis in a nonendemic area (2008-2011). Journal of Equine Veterinary Science, 33, 653-657. 
Soares, C.O., Ishikawa, M.M., Fonseca, A.H., Yoshinari, N.H., 2000. Borrelioses, agents and vectors: a review. Pesquisa Veterinária Brasileira, 20, 1-19.

Socoloski, S.N.G., De Castro, B.G., Cordeiro, M.D., Da Fonseca, A.H., Cepeda, M.B., Nicolino, R.R., Lopes, L.B., 2018. Epidemiological investigation of Borrelia burgdorferi in horses in the municipality of Sinop-MT, Brazil. Tropical Animal Health and Production, 50(4), 831-836.

Souza, C.E., Moraes-Filho, J., Ogrzewalska, M., Uchoa, F.C., Horta, M.C., Souza, S.S., Borba, R.C., Labruna, M.B., 2009. Experimental infection of capybaras Hydrochoerus hydrochaeris by Rickettsia rickettsii and evaluation of the transmission of the infection to ticks Amblyomma cajennense. Veterinary Parasitology, 161(1-2), 116-121.

Souza, C.E., Camargo, L.B., Pinter, A., Donalisio, M.R., 2016. High Seroprevalence for Rickettsia rickettsii in Equines Suggests Risk of Human Infection in Silent Areas for the Brazilian Spotted Fever. PLoS One, 11(4), e0153303.

Stevenson, M., 2005. An Introduction to Veterinary Epidemiology. Palmerston North. IVABS Massey Univ EpiCentre 109.

Szabó, M.P., Pinter, A., Labruna, M.B., 2013. Ecology, biology and distribution of spotted-fever tick vectors in Brazil. Frontiers in Cellular and Infection Microbiology, 12(3), 27.

Talagrand-Reboul, E., Raffetin, A., Zachary, P., Jaulhac, B., Eldin, C., 2020. Immunoserological Diagnosis of Human Borrelioses: Current Knowledge and perspectives. Frontiers in Cellular and Infection Microbiology, 19(10), 241.
Thompson, J.D., Higgins, D.G., Gibson, T.J., 1994. CLUSTAL W: improving the sensitivity of progressive multiple sequence alignment through sequence weighting, position-specific gap penalties and weight matrix choice. Nucleic Acids Research, 22(22), 4673-4680.

Ueno, T.E., Costa, F.B., Moraes-Filho, J., Agostinho, W.C., Fernandes, W.R., Labruna, M.B., 2016. Experimental infection of horses with Rickettsia rickettsii. Parasites \& Vectors, 9(1), 499.

Vieira, T.S., Vieira, R.F., Krawczak, F.S., Soares, H.S., Guimarães, A.M., Barros-Filho, I.R., Marcondes, M., Labruna, M.B., Biondo, A.W., Vidotto, O., 2016. Ehrlichia sp. infection in carthorses of low-income owners, Southern Brazil. Comparative Immunology, Microbiology \& Infectious Diseases, 48, 1-5.

Widmer, C.E., Azevedo, F.C., Almeida, A.P., Ferreira, F., Labruna, M.B., 2011. Tick-borne bacteria in free-living jaguars (Panthera onca) in Pantanal, Brazil. Vector-Borne and Zoonotic Diseases, 11(8), 1001-1005.

Yparraguirre, L.A., Machado-Ferreira, E., Ullmann, A.J., Piesman, J., Zeidner, N.S., Soares, C.A., 2007. A hard tick relapsing fever group spirochete in a Brazilian Rhipicephalus (Boophilus) microplus. Vector-Borne and Zoonotic Diseases, 7(4), 717-721.

Publisher's Note Springer Nature remains neutral with regard to jurisdictional claims in published maps and institutional affiliations. 